\title{
On Exploration and then Establishing the Inter- relationships amongst the Challenges in Implementing Digital Divide in India
}

\author{
Bina Dhari Lal Aggarwal \\ Recventures Education \\ Services Private Limited \\ Delhi, India
}

\author{
Lakshay Aggarwal \\ Recventures Education \\ Services Private Limited \\ Delhi, India
}

\author{
Remica Aggarwal \\ Recventures Education \\ Services Private Limited \\ Delhi, India
}

\begin{abstract}
Present research focuses on studying various challenges associated with implementation of digital divide in India. It thereafter studies the inter-relationship amongst them using ISM methodology.
\end{abstract}

\section{Keywords}

Digital Divide; Interpretive Structural Modelling Methodology ; Social media

\section{INTRODUCTION}

Digital divide $a . k . a$ DD have been conceptualised as a binary term referring to the "haves" and "have nots" of technology equipment and the ability to access the Internet ${ }^{1}$. As per ALA $^{1}$, these "haves" and "have nots" consider the factors such as gender, race, income, primary language, geographic location, physical and mental abilities, educational status, and generational characteristics. It was observed that over the last decade, despite the fact that $100 \%$ of public schools within America reported to have one or more computers available for educational purposes with Internet access to and use of, home and school computers among K-12 students remain unequal [1]. According to researchers, the digital divide within K-12 schools can be described employing a three-level theoretical model [2]. The first level of the model being the equitable access to technological equipment, resources, and support within a school; second level being how frequent the digital resources are being utilized as well as the reason for being used by students and instructors within the classroom [2]. Finally, the third level focuses on the ways that technologies are being used to empower people within the context of their education. The incorporation of information technology in learning has drastically transformed the society especially to those who can access the services but the huge disparity in access to information and communication technology can be either geographical or socio-economical, and the education sector is adversely affected by this rift. The education factor in digital divide is like the dilemma of egg and chicken: both are interrelated and knowing which one precipitate the other is difficult.

Prior to the late 20th century, the concept of digital divide was interpreted solely as the gap between those with and without telephone access. However, from the late 1990s, digital divide [ as split between those with and without access ] with a wider interpretation, being referred to as the existential gap between those with access to modern information and communications technology and those that don't or have restricted access. However, this divide is shrinking steadfastly at a rate of $5 \%$ annually and internet growth statistics show that by the year 2028, $100 \%$ of the world population will have internet access.

The paper is arranged as follows: Section 2 describes the factors affecting the digital divide in India. section 3 describes the ISM methodology and thereafter section 4 describes the case example.

\section{LITERATURE REVIEW ON MEASURING THE EFFECT OF SOCIAL MEDIA}

Despite the exemplary growth in the number of people accessing the internet over the years, there still remains approximately 3.5 billion people worldwide today who have no internet access. A huge percentage of these people are located in less developed countries and more particularly in the rural areas where the infrastructure development is very poor. Following are some of the factors which contribute to this divide $\left.{ }^{[1-17}\right],[1-5]$ :

2.1 Gender and Age bias [GAB] : It is stated that in some countries and organizations, female have less access to the Internet than males while in others it was found that fewer male (38\%) had limited access to the Internet than female $(41 \%)$. This disparity is partly attributed to perception that IT is a technical subject for men, with many female consequently shying away from it (Mutula 2002; Singh 2004). Also, it is clear that a digital divide exists between age groups because the youth are more exposed to technology and are willing to use it, whereas older people are resistant to change and avoid the use of technology [Singh, 2001; Singh ,2004] .

2.2 Physical disability [PD] : Visually impaired and blind people are fully able to use a computer due to advances in technology such as Jaws, which is one of many screen readers. Screen readers are voice synthesizers that can read thetext on a screen. However the Internet is inaccessible to the blind and visually impaired user because the screen reader is unable to read the graphically based web page(Cullen, 2001).

2.3 Lack of Infrastructure / ICT Support [ LOI] ： Lack of telecommunication infrastructure with sufficient reliable bandwidth for Internet connections and cost, the ability to purchase, rent without financial hardship and the necessary equipment. This result in lack of access to technology (Hardware and software. People in many disadvantaged groups are often precluded from making use of ICTs because of low levels of computing an technology skills and also very importantly literacy skills. This is significant factor in preventing certain people from using the internet technologies (Salinas 2003). 
2.4 Attitudinal factors [AF]: This derived from cultural and behavioral attitudes towards technology. Checking emails and searching for information are the two most popular reasons for accessing net over mobile phones. 2.8\% of Urban Indian mobile population used the Internet over their phones to check emails while $2.5 \%$ used the net to search for information

2.5 Irrelevant Content [IC] : There is a section of people such as elderly or women segment who avoid using the internet technologies because of disinteresting and irrelevant content . (Cullen 2001; Salinas 2003).

2.6 Complex Socio-economic conditions [CSEC] : As India is a multicultural, multi-language and multi-religion country with complex socio-economic conditions, there are many difficulties such as poverty, unemployment, age and education in serving rural communities.

2.7 Gap between digital divide between rural and urban India [ GDD] : In situations of biased growth in favour of urban areas, more than $75 \%$ of the broadband connections in the country are in the top 30 cities. This becomes one of the strong reasons for digital divide between those living in rural areas and those living in urban areas, and on a global scale between more and less industrially developed nations.

2.8 Knowledge and education Divide [KED] : Knowledge divide is directly related with digital divide. One of the biggest challenges which face Indian education is the number of dropouts at the undergraduate level. Approximately 23 million children per year take up primary education but only about 15 million children per year take up secondary education. This figure gets drastically reduced at the undergraduate level to only about 2.3 million students per year (Yajnik, 2005).

2.9 Delay in implementation of govt. policies [DIP] : Growing population, insufficient funds, affordability and delays in implementation of government policies and programmes are some of the miscellaneous challenges that have led to unequal development in the society, which is responsible for digital divide.

2.10 Literacy and skill barriers [LSB]: The lack of skill and education in information literacy in using computer and communication technology prevents people from accessing digital information.

2.11 Economic barriers [EB] : There is an economic and financial constraint which causes the digital divide. In India the ability to purchase or rent the tool for access to digital information is less among the masses.

2.12 Language barriers [LB]: A large percentage of information content on the internet is in English which becomes the barrier for the people whose primary language is not English. For Indians who speak no (or little) English, the barriers to the Information Age are almost inseparable.

2.13 Lack of exploitation of full potential [LEFP]: There is a lack of full potential of individuals hailing from low income families as they have limited access to information advancing their education and web connectivity and therefore coming up with innovative ideas is difficult .

2.14 Unfair competitive edge [UCE]: Presently, due to wider embracement of technology, most activities including assignments and presentation of learning material are made available online. This gives superior students who can access the internet unfair competitive edge over their less privileged counterparts.

\section{INTERPRETIVE STRUCTURAL MODELLING METHODOLOGY [ISM ]}

Proposed by Warfield [6], ISM methodology is a technique for establishing inter-relationships amongst the criteria of interest. The process begins with the identification of relevant elements and thereafter establishing contextual relationship amongst them . After that the structural self - interaction matrix is created using the VAXO concept which is then followed by the creation of initial reachability matrix . Final reachability matrix is then created after correcting the initial reachability matrix for any possibility of transitivity. From the reachability matrix, the reachability set and antecedent set for each criterion is found [6]. Then the intersection of these sets is derived for all elements. The element for which the reachability and intersection sets are the same is the top-level element. Then the reachability matrix is converted into the canonical matrix format by arranging the elements according to their levels. Based on the relative driving power and dependence power, factors are classified in various categories like autonomous, dependent, driver and linkage. Finally, a diagraph is constructed from the canonical matrix .

\section{DEVELOPMENT OF ISM MODEL CASE EXAMPLE}

Based on the exploratory research , around 14 barriers have been recognized viz. Gender and age bias [GAB]; Physical disability [PD]; Lack of Infrastructure / ICT Support [LOI]; Attitudinal factors [AF]; Irrelevant Content [IC] ; Complex Socio-economic conditions [CSEC]; Gap between digital divide between rural and urban India [GDD] ; Knowledge and education Divide [KED]; Delay in implementation of govt. policies [DIP]; Literacy and skill barriers [LSB] ; Economic barriers [EB]; Language barriers [LB]; Lack of exploitation of full potential [LEFP] ; Unfair competitive edge [UCE]which can be studied further for possible inter-relationships amongst them using ISM methodology .

\subsection{Construction of Structural self- interaction Matrix (SSIM)}

This matrix gives the pair-wise relationship between two variables i.e. $i$ and $j$ based on VAXO. SSIM has been presented below in Fig 1.

\subsection{Construction of Initial Reachability Matrix and final reachability matrix}

The SSIM has been converted in to a binary matrix called the Initial Reachability Matrix shown in fig. 2 by substituting V, $\mathrm{A}, \mathrm{X}, \mathrm{O}$ by 1 or 0 as per the case. After incorporating the transitivity, the final reachability matrix is shown below in the Fig 3.

Fig 1: SSIM matrix for pair wise relationship amongst barriers

\begin{tabular}{|c|c|c|c|c|c|c|c|c|c|c|c|c|c|c|c|}
\hline $\begin{array}{c}\text { S. } \\
\text { No. }\end{array}$ & Barriers & 1 & 2 & 3 & 4 & 5 & 6 & 7 & 8 & 9 & 10 & 11 & 12 & 13 & 14 \\
\hline & & GAB & PD & LOI & AF & IC & CSEC & GDD & KED & DIP & LSB & EB & LB & LEFP & UCE \\
\hline
\end{tabular}




\begin{tabular}{|c|c|c|c|c|c|c|c|c|c|c|c|c|c|c|}
\hline 1 & GAB & $\mathrm{O}$ & $\mathrm{V}$ & $\mathrm{V}$ & $\mathrm{O}$ & $\mathrm{A}$ & $\mathrm{A}$ & $\mathrm{A}$ & $\mathrm{A}$ & $\mathrm{X}$ & A & $\mathrm{O}$ & $\mathrm{V}$ & $\mathrm{V}$ \\
\hline 2 & PD & & $\mathrm{O}$ & V & $\mathrm{O}$ & A & $\mathrm{V}$ & $\mathrm{O}$ & A & $\mathrm{V}$ & V & $\mathrm{O}$ & $\mathrm{V}$ & $\mathrm{V}$ \\
\hline 3 & LOI & & & $\mathrm{V}$ & $\mathrm{V}$ & $\mathrm{A}$ & $\bar{A}$ & $\mathrm{~V}$ & $\mathrm{~A}$ & $\mathrm{~V}$ & $\mathrm{~A}$ & $\mathrm{X}$ & $\mathrm{V}$ & $\mathrm{V}$ \\
\hline 4 & $\overline{\mathrm{AF}}$ & & & & $\mathrm{A}$ & $\mathrm{A}$ & $\mathrm{A}$ & $\mathrm{A}$ & $\mathrm{A}$ & $\mathrm{A}$ & A & A & A & A \\
\hline 5 & IC & & & & & $\mathrm{O}$ & $\mathrm{A}$ & $\mathrm{A}$ & $\mathrm{A}$ & $\mathrm{A}$ & $\mathrm{A}$ & $\mathrm{A}$ & $\mathrm{A}$ & $\bar{A}$ \\
\hline 6 & CSEC & & & & & & $\mathrm{X}$ & $\mathrm{V}$ & A & $\mathrm{V}$ & $\mathrm{V}$ & $\mathrm{V}$ & $\mathrm{V}$ & $\mathrm{V}$ \\
\hline 7 & GDD & & & & & & & $\mathrm{A}$ & A & $\mathrm{V}$ & $\mathrm{V}$ & $\mathrm{V}$ & $\mathrm{V}$ & $\mathrm{V}$ \\
\hline 8 & KED & & & & & & & & A & $\mathrm{V}$ & $\mathrm{X}$ & $X$ & $\mathrm{~V}$ & $\mathrm{~V}$ \\
\hline 9 & DIP & & & & & & & & & $\mathrm{V}$ & $\mathrm{V}$ & V & $\mathrm{V}$ & $\mathrm{V}$ \\
\hline 10 & LSB & & & & & & & & & & A & A & A & $\mathrm{V}$ \\
\hline 11 & EB & & & & & & & & & & & $\mathrm{V}$ & V & V \\
\hline 12 & LB & & & & & & & & & & & & $\mathrm{V}$ & $\mathrm{V}$ \\
\hline 13 & LEFP & & & & & & & & & & & & & A \\
\hline 14 & UCE & & & & & & & & & & & & & \\
\hline
\end{tabular}

Fig 2: Initial reachability matrix

\begin{tabular}{|c|c|c|c|c|c|c|c|c|c|c|c|c|c|c|c|}
\hline $\begin{array}{c}\text { S. } \\
\text { No. }\end{array}$ & Barriers & 1 & 2 & 3 & 4 & 5 & 6 & 7 & 8 & 9 & 10 & 11 & 12 & 13 & 14 \\
\hline & & GAB & PD & LOI & AF & IC & CSEC & GDD & KED & DIP & LSB & EB & LB & LEFP & UCE \\
\hline 1 & GAB & 1 & 0 & 1 & 1 & 0 & 0 & 0 & 0 & 0 & 1 & 0 & 0 & 1 & 1 \\
\hline 2 & PD & 0 & 1 & 0 & 1 & 0 & 0 & 1 & 0 & 0 & 1 & 1 & 0 & 1 & 1 \\
\hline 3 & LOI & 0 & 0 & 1 & 1 & 1 & 0 & 0 & 1 & 0 & 1 & 0 & 1 & 1 & 1 \\
\hline 4 & AF & 0 & 0 & 0 & 1 & 0 & 0 & 0 & 0 & 0 & 0 & 0 & 0 & 0 & 0 \\
\hline 5 & IC & 0 & 0 & 0 & 1 & 1 & 0 & 0 & 0 & 0 & 0 & 0 & 0 & 0 & 0 \\
\hline 6 & CSEC & 1 & 1 & 1 & 1 & 0 & 1 & 1 & 1 & 0 & 1 & 1 & 1 & 1 & 1 \\
\hline 7 & GDD & 1 & 0 & 1 & 1 & 1 & 1 & 1 & 0 & 0 & 1 & 1 & 1 & 1 & 1 \\
\hline 8 & KED & 1 & 0 & 0 & 1 & 1 & 0 & 1 & 1 & 0 & 1 & 1 & 1 & 1 & 1 \\
\hline 9 & DIP & 1 & 1 & 1 & 1 & 1 & 1 & 1 & 1 & 1 & 1 & 1 & 1 & 1 & 1 \\
\hline 10 & LSB & 1 & 0 & 0 & 1 & 1 & 0 & 0 & 0 & 0 & 1 & 0 & 0 & 0 & 1 \\
\hline 11 & EB & 1 & 0 & 1 & 1 & 1 & 0 & 0 & 1 & 0 & 1 & 1 & 1 & 1 & 1 \\
\hline 12 & LB & 0 & 0 & 1 & 1 & 1 & 0 & 0 & 1 & 0 & 1 & 0 & 1 & 1 & 1 \\
\hline 13 & LEFP & 0 & 0 & 0 & 1 & 1 & 0 & 0 & 0 & 0 & 1 & 0 & 0 & 1 & 0 \\
\hline 14 & UCE & 0 & 0 & 0 & 1 & 1 & 0 & 0 & 0 & 0 & 1 & 0 & 0 & 1 & 1 \\
\hline
\end{tabular}

Fig 3 : Final reachability matrix

\begin{tabular}{|c|c|c|c|c|c|c|c|c|c|c|c|c|c|c|c|c|}
\hline $\begin{array}{c}\text { S. } \\
\text { No. }\end{array}$ & Barriers & 1 & 2 & 3 & 4 & 5 & 6 & 7 & 8 & 9 & 10 & 11 & 12 & 13 & 14 & D.P \\
\hline & & GAB & PD & LOI & AF & IC & CSEC & GDD & KED & DIP & LSB & EB & LB & LEFP & UCE & \\
\hline 1 & GAB & 1 & 0 & 1 & 1 & 1 & 0 & 0 & 0 & 0 & 1 & 0 & 0 & 1 & 1 & 7 \\
\hline 2 & PD & 1 & 1 & 1 & 1 & 1 & 0 & 1 & 1 & 0 & 1 & 1 & 1 & 1 & 1 & 12 \\
\hline 3 & LOI & 1 & 0 & 1 & 1 & 1 & 0 & 0 & 1 & 0 & 1 & 0 & 1 & 1 & 1 & 8 \\
\hline 4 & AF & 0 & 0 & 0 & 1 & 0 & 0 & 0 & 0 & 0 & 0 & 0 & 0 & 0 & 0 & 1 \\
\hline 5 & IC & 0 & 0 & 0 & 1 & 1 & 0 & 0 & 0 & 0 & 0 & 0 & 0 & 0 & 0 & 2 \\
\hline 6 & CSEC & 1 & 1 & 1 & 1 & 1 & 1 & 1 & 1 & 0 & 1 & 1 & 1 & 1 & 1 & 13 \\
\hline
\end{tabular}




\begin{tabular}{|c|c|c|c|c|c|c|c|c|c|c|c|c|c|c|c|c|}
\hline 7 & GDD & 1 & 1 & 1 & 1 & 1 & 1 & 1 & 1 & 0 & 1 & 1 & 1 & 1 & 1 & 13 \\
\hline 8 & KED & 1 & 1 & 1 & 1 & 1 & 0 & 1 & 1 & 0 & 1 & 1 & 1 & 1 & 1 & 12 \\
\hline 9 & DIP & 1 & 1 & 1 & 1 & 1 & 1 & 1 & 1 & 1 & 1 & 1 & 1 & 1 & 1 & 14 \\
\hline 10 & LSB & 1 & 0 & 1 & 1 & 1 & 0 & 0 & 0 & 0 & 1 & 0 & 0 & 1 & 1 & 7 \\
\hline 11 & EB & 1 & 0 & 1 & 1 & 1 & 0 & 0 & 1 & 0 & 1 & 1 & 1 & 1 & 1 & 10 \\
\hline 12 & LB & 1 & 0 & 1 & 1 & 1 & 0 & 1 & 1 & 1 & 1 & 1 & 1 & 1 & 1 & 12 \\
\hline 13 & LEFP & 0 & 0 & 0 & 1 & 1 & 0 & 0 & 0 & 0 & 1 & 0 & 0 & 1 & 1 & 5 \\
\hline 14 & UCE & 1 & 0 & 0 & 1 & 1 & 0 & 0 & 0 & 0 & 1 & 0 & 0 & 1 & 1 & 6 \\
\hline & De.P & 11 & 5 & 9 & 14 & 13 & 3 & 6 & 8 & 2 & 12 & 7 & 6 & 12 & 12 & \\
\hline
\end{tabular}

D.P : Driving Power ; De.P : Dependence Power

\subsection{Level Partition}

From the final reachability matrix, reachability and final antecedent set for each factor are found. The elements for which the reachability and intersection sets are same are the top-level element in the ISM hierarchy. After the identification of top level element, it is separated out from the other elements and the process continues for next level of elements. Reachability set, antecedent set, intersection set along with different level for elements have been shown below in table 1 to table 11 .

Table 1: Iteration I

\begin{tabular}{|c|c|c|c|c|}
\hline $\begin{array}{l}\text { S. } \\
\text { No }\end{array}$ & Reachability set & Antecedent set & $\begin{array}{l}\text { Intersec } \\
\text { tion set }\end{array}$ & $\begin{array}{c}\text { Lev } \\
\text { el }\end{array}$ \\
\hline 1 & 4 & $\begin{array}{l}1,2,3,4,5,6,7,8,9 \\
10,11,12,13,14\end{array}$ & 4 & \\
\hline 2 & 4,5 & $\begin{array}{c}, 2,3,5,6,7,8,9,1 \\
0,11,12,13,14\end{array}$ & 5 & \\
\hline 3 & $4,5,10,13,14$ & $\begin{array}{c}1,2,3,6,7,8,9,10, \\
11,12,13,14\end{array}$ & $10,13,14$ & \\
\hline 4 & $1,4,5,10,13,14$ & $\begin{array}{c}1,2,3,6,7,8,9,10, \\
11,12,14\end{array}$ & $\mathbf{1}, 10,14$ & \\
\hline 5 & $1,3,4,5,10,13,14$ & $\begin{array}{c}1,2,3,6,7,8,9,10, \\
11,12\end{array}$ & $1,3,10$ & \\
\hline 6 & $\begin{array}{c}1,3,4,5,8,10,13 \\
14\end{array}$ & $\begin{array}{c}1,2,3,6,7,8,9,11, \\
12\end{array}$ & $1,3,8$ & \\
\hline 7 & $\begin{array}{c}1,3,4,5,8,10,11,1 \\
3,14\end{array}$ & $\begin{array}{c}1,2,6,7,8,9,11,1 \\
2\end{array}$ & $1,8, \mathbf{1 1}$ & \\
\hline 8 & $\begin{array}{c}1,3,4,5,8,10,11,1 \\
2,13,14\end{array}$ & $2,6,7,8,9,11,12$ & $8,11, \mathbf{1 2}$ & \\
\hline 9 & $\begin{array}{c}1,2,3,4,5,7,8,10,1 \\
1,12,13,14\end{array}$ & $2,6,7,8,9$ & $2,7,8$ & \\
\hline 10 & $\begin{array}{c}1,2,3,4,5,6,7,8,10 \\
11,12,13,14\end{array}$ & $6,7,9$ & 6,7 & I \\
\hline 11 & $\begin{array}{c}1,2,3,4,5,6,7,8,9 \\
10,11,12,13,14\end{array}$ & 9 & 9 & \\
\hline
\end{tabular}

\section{ACKNOWLEDGEMENTS}

Authors extend their deepest regards to Dr. Ajita Deshmukh , MIT-SOER, MIT-ADT university for the inspiration in Digital divide and also to Dr. S.P Singh, DMS , IIT Delhi for the knowledge dissemination in ISM Methodology which has helped them substantially in preparation of this manuscript . Author Lakshay Aggarwal also pays his sincere regards to IGNOU, Delhi for the Psychology course which has made him contribute significantly to this manuscript.

\section{CONCLUSIONS}

Present paper is an application based research which studies the inter-relationship amongst various constraints leading to digital divide

\section{REFERENCES}

[1] Dolan, JE. 2016. Splicing the divide: A review of research on the evolving digital divide among $\mathrm{K}-12$ students. Journal of Research on Technology in Education, $\quad 48(1)$, 16-37. DOI: https://doi.org/10.1080/15391523.2015.1103147

[2] Hohlfeld, T.N., Ritzhaupt , A.D., Kemker, K. 2008. Examining the digital divide in K-12 public schools: Four-year trends for supporting ICT literacy in Florida, Article in Computers \& Education 51(4),1648-1663 . DOI: 10.1016/j.compedu.2008.04.002 .

[3] Cullen, R. 2001. Addressing the digital divide. Online information review, 25 (5): 311-320.

[4] Paul, J. 2002. Narrowing the digital divide: initiatives undertaken by the Association of South-East Asian Nations (ASEAN). Program: electronic library and information systems 36(1), 13-22.

[5] Salinas, R. 2003. Addressing the digital divide through collection development. Collection building, 22(3), 131136.

[6] Warfield, J.N. 1974. Developing interconnection matrices in structural modeling. IEEE Transactions on Systems, Man, and Cybernetics, (1), 81-87.

\section{APPENDIX}

Various Government and public private partnership projects /Policy/Programmes for Addressing the Challenges in Bridging the Digital Divide [1-3]

- Sourkaryan and E-Seva P Andhra Pradesh's government provides the facility for a citizen to pay property taxes online and also view details of plans and projects of the government and local bodies.

- Madhya Pradesh's Gyandoot Project, is known for providing "Soochnalayas" at prominent market 
places or major roads wherein people can easily log in and complain or request information on crops, forest fields, water resources, etc. of the district.

- Microsoft's community technology skills programme, which was launched in 2004 in India and 2005 in Chennai, is known for providing their new programme 'Youth Spark', which will focus on holistic education and developing entrepreneurship skills

- Centre for Advanced Computing (C-DAC) based in Pune, aims to bring about one million digital books to the doorsteps of common citizens. In promoting literacy, it will make use of a mobile van with satellite Internet connections. This van will be fitted with printers, scanners, cutters and binding machines for providing books in bound form to end users.

- Unnati, a project of the Hindustan Petroleum Corporation Limited (HPCL)strives to bridge the digital divide in schools by giving poor economic and social background rural students an access to computer education by supplying computers for each school.

- The Azim Premji Foundation has been involved with universalization of elementary education by creating effective and scalable models to improve the quality of learning in school.

- Tata Council of Community Initiatives, has extended several innovative computer-based literacy programs to improve India's adult education by preparing multimedia presentations.

- Role of digital divide in languages and foreign language ${ }^{5}$ : The projects like Gyanadoot at Dhar (MP), Wired Village at Warna (Maharashtra), MS Swaminathan foundation's project at Veerampattinam (Pondicherry), Collectorate of Thiruvarur (Tamil Nadu) reported in (Sothik Biswas, 2001)have demonstrated how the innovative IT projects executed by the committed agencies have facilitated in bridging the digital divide.

- TDIL (Technology Development for Indian Languages) develops information processing tools and techniques to facilitate human-machine interaction without language barrier; creating and accessing multilingual knowledge resources; and integrating them to develop innovative user products and services.

- The Bhoomi Project of Karnataka state covers 6.7 million farmers and holds millions of records of land ownership is known for reducing the delays involved in interacting with the bureaucratic hierarchy of the state revenue department.

- Kisan Call centre: The Department of Agriculture \& Cooperation (DAC), Ministry of Agriculture, Govt. of India launched Kisan Call Centers on January 21, 2004 across the country to deliver extension services to the farming community; addressing issues raised by farmers, instantly, in the local language. 